\title{
Phenotypic traits and environment strongly predict seedling survival for seven co-occurring Great Basin plant taxa growing with invasive grass
}

\author{
Alison Agneray ${ }^{1}$, Thomas Parchman ${ }^{2}$, and Elizabeth Leger ${ }^{1}$ \\ ${ }^{1}$ University of Nevada, Reno \\ ${ }^{2}$ University of Nevada Reno
}

November 3, 2021

\begin{abstract}
Trait-environment correlations can arise from local adaptation and can identify genetically and environmentally appropriate seeds for restoration projects. However, anthropogenic changes can disrupt the relationships between traits and fitness. Finding the best seed sources for restoration may rely on describing plant traits adaptive in disturbed and invaded environments, recognizing that while traits may differ among species and functional groups, there may be similarities in the strategies that increase seedling establishment. Focusing on three grass genera, two shrub species, and two forb genera, we collected seeds of all taxa from 16 common sites in the sagebrush steppe of the western United States. We measured seed and seedling characteristics, including seed size, emergence timing, and root and shoot traits, and compiled a suite of environmental variables for each collection site. We described trait-environment associations and asked how traits or environment of origin were associated with seedling survival in invaded gardens. Sampling seven taxa from the same sites allowed us to ask how trait-environmentperformance associations differ among taxa and whether natural selection favors similar traits across multiple taxa and functional groups. All taxa showed trait-environment associations consistent with local adaptation, and both environment of origin and phenotypic traits predicted survival in competitive restoration settings, with some commonalities among taxa. Notably, rapid emergence and larger seeds increased survival for multiple taxa. Environmental factors at collection sites, including lower slopes (especially for grasses), greater mean annual temperatures (especially for shrubs and forbs), and greater precipitation seasonality were frequently associated with increased survival. We noted one collection site with high seedling survival across all seven taxa, suggesting that conditions within some sites may result in selection for traits that increase establishment for multiple species. Thus, choosing native plant sources with the most adaptive traits, along with matching climates, will likely improve the restoration of invaded communities.
\end{abstract}

\section{Hosted file}

MainDocument.docx available at https://authorea.com/users/444375/articles/544110-phenotypictraits-and-environment-strongly-predict-seedling-survival-for-seven-co-occurring-greatbasin-plant-taxa-growing-with-invasive-grass 


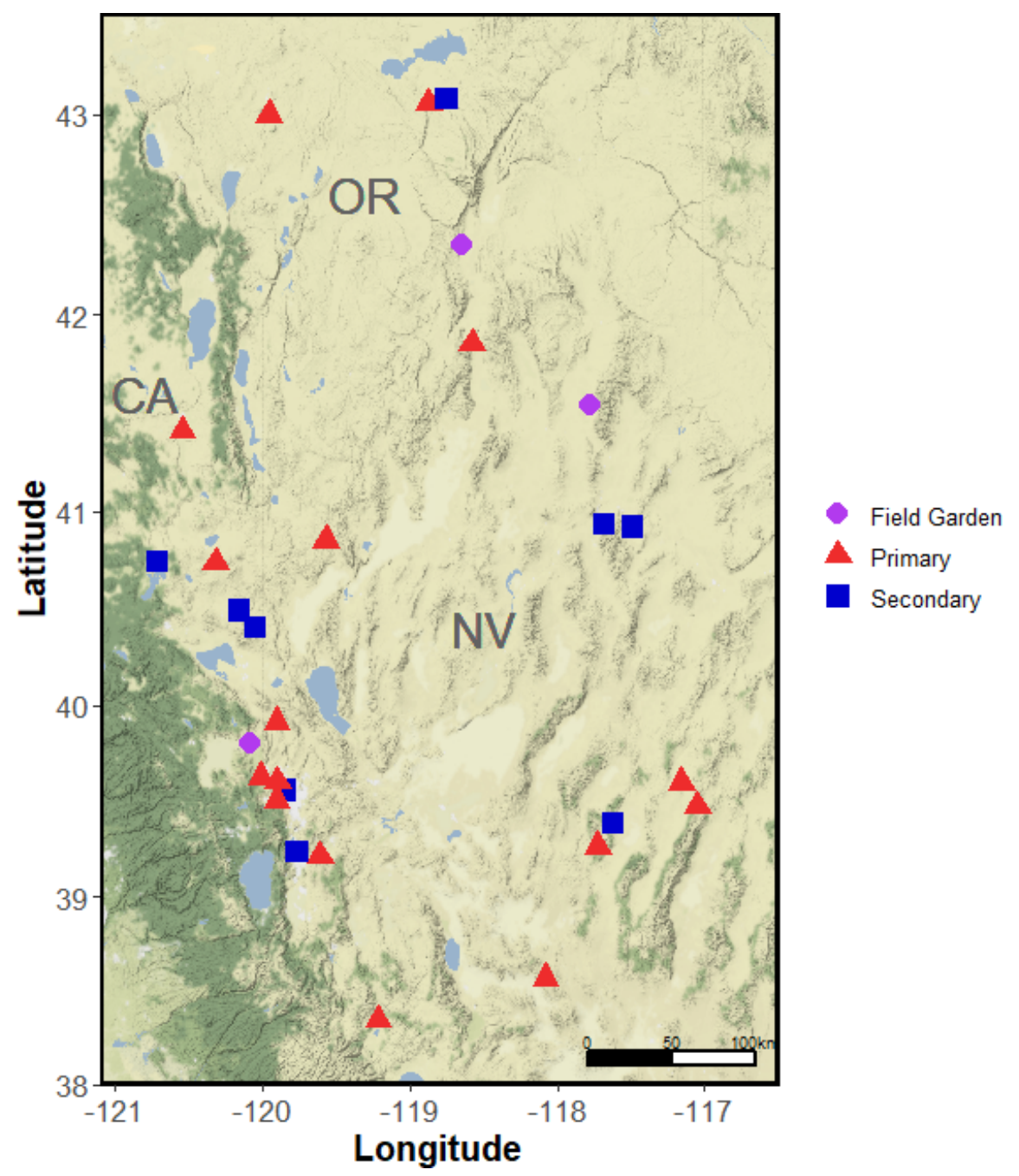




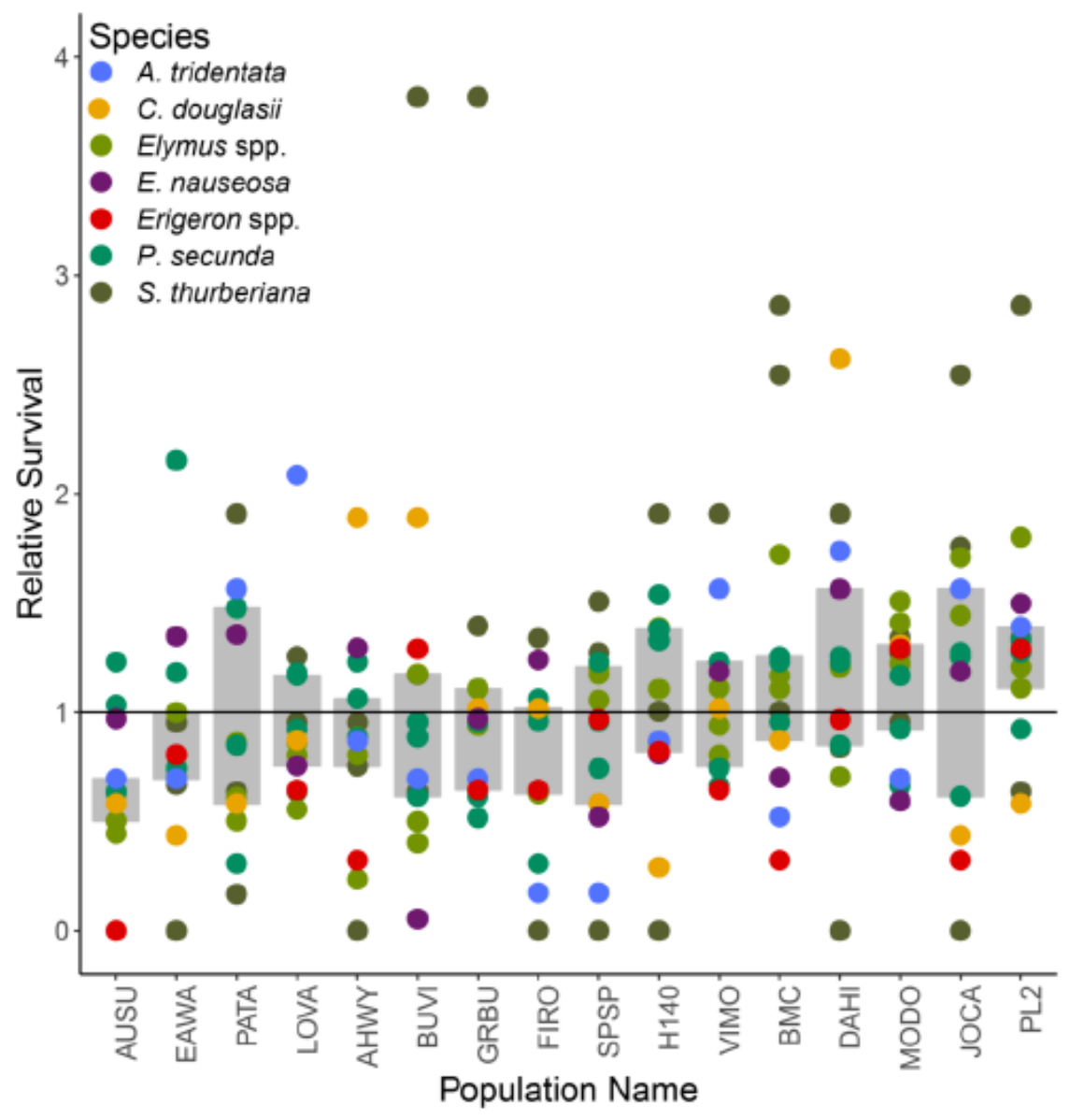



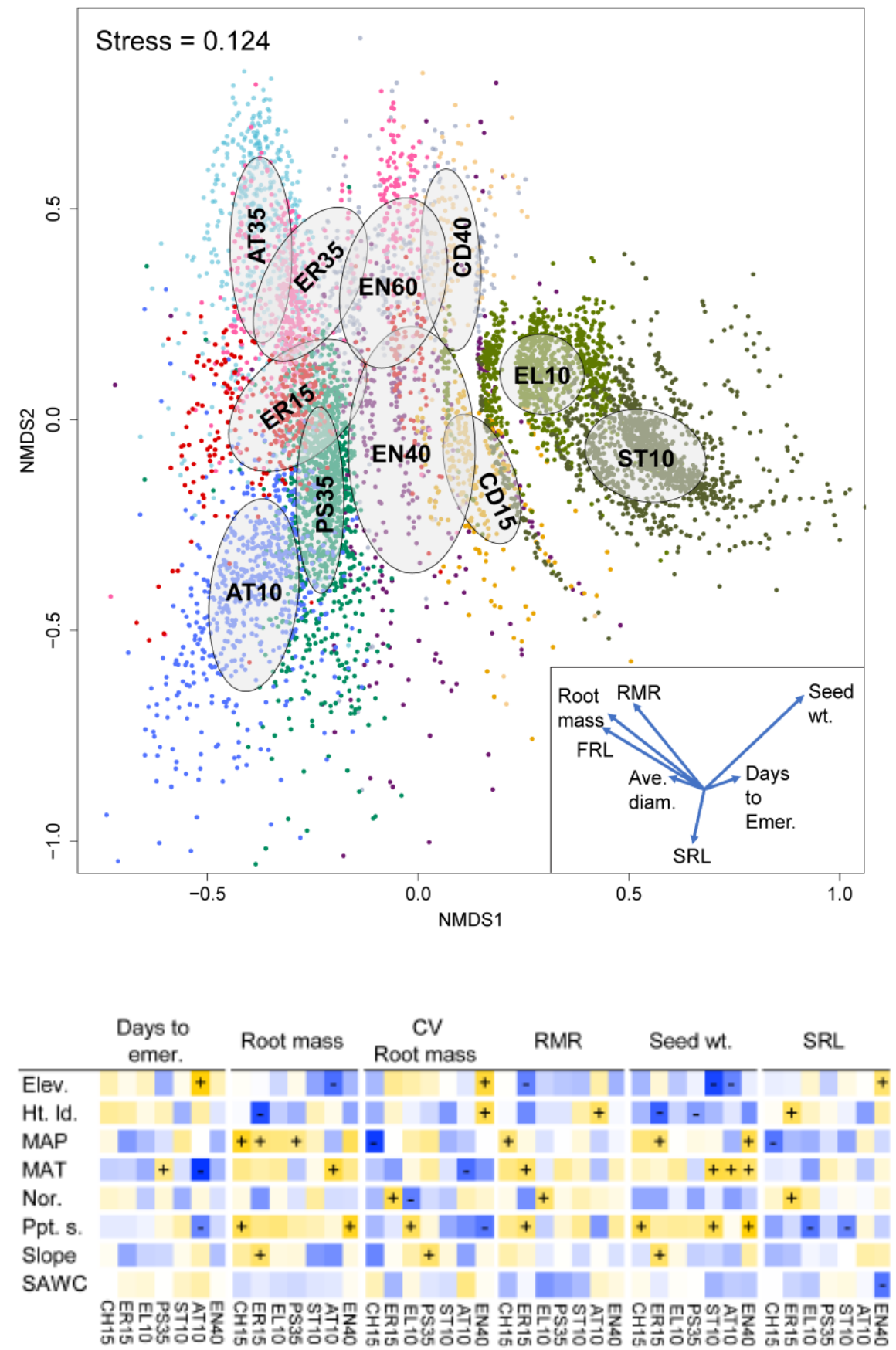

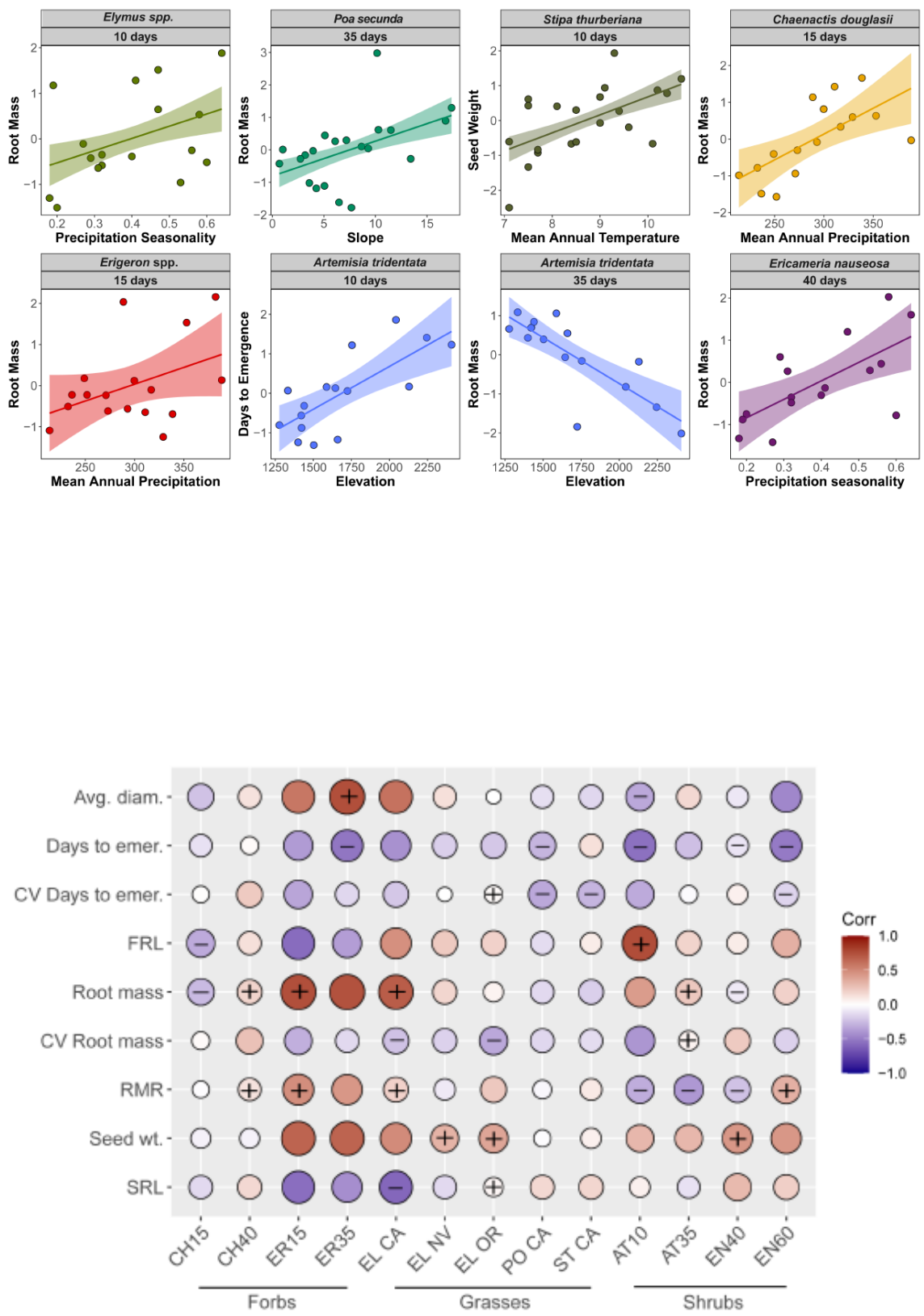


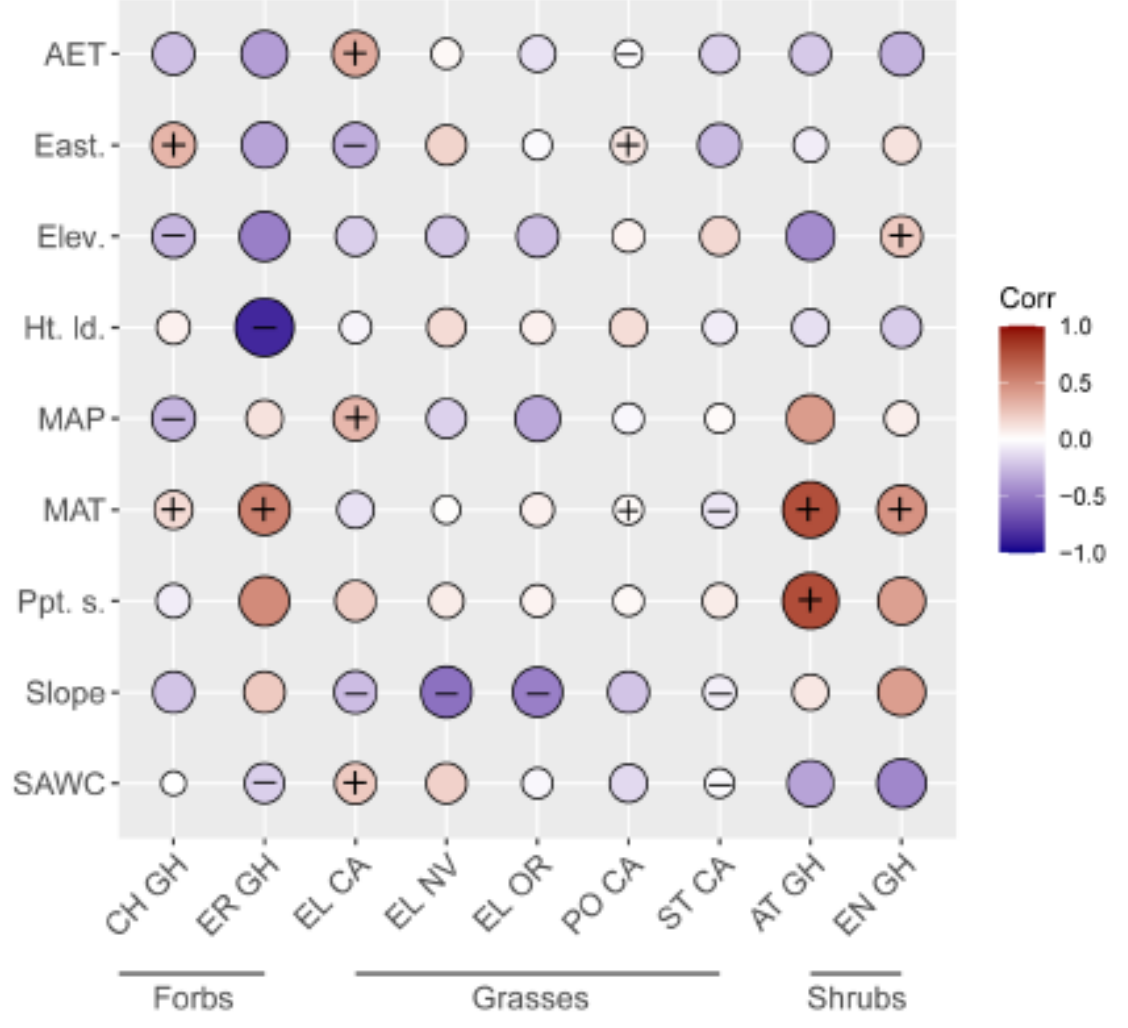

